\title{
Vitamin D3 and Selenium Supplementation and Renal Hyper-filtration State in Metabolic Syndrome Patients
}

\author{
Muhammad A. Ahmed ${ }^{1, *}$ \\ ${ }^{1}$ University of Nineveh college of Medicine \\ *Corresponding author. Email:moh1977729@gmail.com
}

\begin{abstract}
Objective: This work aimed to study the effect of supplanting vitamin D3 and selenium on the renal-filtration status and glycosylation- gap in metabolic syndrome patients. Subjects and methods: This pre-post study conducted on 93 patients referred from different general /or private internal medicine clinics with metabolic syndrome to the Soran private laboratory-Erbil. Patients present with at least three of five criteria of metabolic syndrome according to NCEP ATP III. Vitamin D estimation using the enzyme-linked fluorescent assay (ELFA) technique. Mitochondrial function analysis involved measurement of serum lactate and serum pyruvate by fluorescence-based methods. L-Carnitine was assayed using colourimetric /fluoro- metric. e-GFR calculated by equation. Results: The results shows that metabolic syndrome patient supplementing with vitamin D3 and selenium significantly elevated serum Vitamin D3 that associated with reduction in both systolic and diastolic blood pressure $(\mathrm{p}<0.001)$. HbAlc, serum fructosamine, Glycosylation gap also significant reduction $(p<0.001)$. Serum triglycerides significantly decrease $(p<0.001)$ with a significant increase in HDL-C $(p<0.001)$. Renal function profile shows that serum creatinine significantly elevated after the treatment in contrast e-GFR, urinary albumin and Albumin/ creatinine ratio reduced after the treatment $(p<0.001)$. Mitochondrial function profile shows that after supplements treatment, mitochondrial function parameters return to normal values in comparison to before treatment $(\mathrm{p}<0.001)$. Conclusion: supplementing vitamin D3 and Selenium to metabolic syndrome patient significantly reduce hyper-filtration status by activating mitochondrial function in these patients, so it can used as a protective measure in the treatment of metabolic syndrome patients.
\end{abstract}

Keywords: Glycosylation gap, metabolic syndrome, renal-filtration, Selenium, mitochondrial function and vitamin D3.

\section{INTRODUCTION}

Metabolic syndrome (MS) is defined as a clustering of risk factors that reflects changes in metabolic activities that lead to developing obesity, ischemic cardiovascular disorders, insulin resistance with diabetes mellitus, dyslipidemia, and neurological complications as CVA or MI1. Patient can be defined to have MS if he/she have any three of the following criteria: waist circumference more than 40 inches in men and 35 inches in women, serum triglycerides more than $150 \mathrm{mg} / \mathrm{dL}$ of blood, low high-density lipoprotein cholesterol (HDL-C) below 40 $\mathrm{mg} / \mathrm{dL}$ in male or less than $50 \mathrm{mg} / \mathrm{dL}$ in female, abnormally high fasting glucose more than $100 \mathrm{mg} / \mathrm{dL}$, hyperuricemia and lastly, blood pressure values 130/85
mmHg1. Besides, the enlarged adipose tissue will produce more pro-inflammatory cytokines e.g. tumour necrosis factor (TNF), leptin, adiponectin, endothelial plasminogen activator inhibitor and adipose tissuespecific secretory factor2. Haller and Hanefeld have first described this syndrome in 1975 where they find that person with MS showed a 1.6-fold increase in mortality3. The complexity of MS aetiology raised from combined genetic and changes lifestyle. Fat mass and obesityassociated protein (FTO) is a single-nucleotide polymorphism, which linked to elevation in BMI and obesity as described by genome-wide association studies (GWAS) since 20074. In MS patients, FTO-gene 
overexpressed and related to the development of both insulin resistance and T2DM4.

MS cause renal impairment by several distinct but inter-connected mechanisms that operating simultaneously to cause renal damage. Multi-risk factors involve such as insulin resistance, inflammation, dyslipidaemia and elevated blood pressure leading to increased expression of connective tissue. Insulin resistance elevates both insulin, Insulin- IGF-1, transforming growth factor-beta (TGF- $\beta$ ), interleukin-6, TNF- $\alpha$ and many pro-inflammatory cytokines5. The inflammation processes produce reactive oxygen species (ROS) that causing oxidative stress status in the renal endothelial cell leads to apoptosis, an abnormal increase in connective tissue that ends with fibrosis and changes infiltration capacity. Oxidative stress changes vascular intima structures and smooth muscle cell growth. Moreover, the elevation in serum triglycerides and free fatty acids in MS patient have nephrotoxic effects 6, 7. Renal hyper-filtration defines, as an increased glomerular filtration rate (GFR) is the main feature of both early type 1 and type 2 diabetes. The elevation of the GFR threshold for hyper-filtration ranged from 120 to $140 \mathrm{ml} / \mathrm{min} / 1.73$ m2 8,9 .

Glycosylation is a non-enzymatic process take place in the plasma and extracellular compartment where proteins react with reducing sugar molecules result in change protein properties and impair their function 10 . Glycosylation gap in (GG) defines as the differences between HbA1c and actual glycaemia value obtained from fructosamine. Also, non-enzymatic glycosylated haemoglobin, glycosylation process target plasma proteins-mainly albumin- and take place in the extracellular compartment. One of the serum glycosylated protein is Fructosamine, which is derive from ketamine products in the serum that can be measured using nitro blue tetrazolium assay. Fructosamine is a reliable indicator of glycaemic control as $\mathrm{HbA1c}$, but with shorter duration due to shorter halflife of serum proteins. In our previous work, we described a significant increase in GG in MS patients as GG associations with worsening retinopathy, elevation in urine albumin/creatinine ratio, in addition to the presence of macrovascular diseases 11, 12. Lactate and pyruvate levels and lactate/pyruvate molar ratio (L/P) represent indirect tool scanning index for mitochondrial function as any changes in cellular respiration change both serum lactate and pyruvate, under normal cellular respiration $\mathrm{L} / \mathrm{P}$ ratio value not excessed 20 while value more than 20 will suggest respiratory chain defective13. L-Carnitine is an important component of inner mitochondrial membrane and plays a vital role in long-chain fatty acid metabolism and energy homeostasis as it a major player in the $\beta$-oxidation process, glycolysis, gluconeogenesis, certain amino acids degradation, detoxification of many organic acids and xenobiotics14,15. No study discussed the role of supplementing patient with vitamin D3 and selenium on mitochondrial function and renal filtration rate.

Aim: This may be first work focus study the effect of supplementing vitamin D3 and Selenium to metabolic syndrome patients on renal-filtration status, glycosylation- gap and mitochondrial function in Mosul.

\section{PATIENTS AND METHODS}

This study is a pre-post study conducted in MosulIraq. Ninety-three patients referred from different general /or private internal medicine clinics with metabolic syndrome to the Soran-private laboratory-Erbil. The study included 49 male and 44 females with an age ranging from 30 to 51 years. Patients present with BMI range from 28-32. All patients referred with their full history review, notes about their clinical examination and laboratory investigations. Patients present with at least three of five criteria of metabolic syndrome according to NCEP ATP III (as we applied in our previous work). Any patient with sever renal impairment, uncontrolled high blood glucose, very high BMI; sever active inflammatory conditions, drugs that can interact with our results was excluded for this work. This study conducted under ethical approval form scientific committee in Nineveh health directorate number 9 that issued in 9/6/2020.

Patients screened for vitamin D estimation that analysed using VIDAS® $25 \mathrm{OH}$ Vitamin D Total BIOMERIEUX - France, for the determination of 25hydroxyvitamin D in serum using the enzyme-linked fluorescent assay (ELFA) technique16. Lipid profile parameters and micro-albumin assay using colorimetric method17. Glycosylation gap calculated using mathematical equation as described in previous work 17. Mitochondrial function analysis involved measurement of serum lactate18 and serum pyruvate19 by fluorescence-based methods of Cayman chemicals (700510 and 700470 respectively) and L-Carnitine was assayed using colourimetric/fluorometric MyBioSource (MBS841446) after standard curve was established20. eGFR was calculated using the $186 \mathrm{x}$ (Creatinine/88.4)$1.154 \times$ (Age)-0.203 x (0.742 if female $) 21$. The entire sample evaluated using Synergy HT-Multi-Detection Micro-Plate Reader (BioTek-Instruments) at a different wavelength as specified by the manufacturer before and after supplementation with specific doses of vitamin D3 and Selenium. Blood pressure was monitored using airfloated upper arm blood pressure monitor Samitrs Hans Dinisiage Company - Germany the results obtained from the mean of 3 successive reading from each patient. HbA1c evaluated by DCA vantage (Siemens).

All patients supplemented with 10-week doses of 25 $\mathrm{mcg}$, which equal $1000 \mathrm{IU} /$ day of vitamin D3, and 200 mcg of selenium standard formula (21st Century healthcare - U.S.A) from Iraqi markets. The patients asked to take the pills half an hour before lunch once daily. Patients on chronic medical regimen excluded 
from this work. Basel vitamin D level did before start the intervention to exclude normo-vitamin D subjects and avoid hyper-vitaminosis. Data represented as mean \pm Standard deviation. Paired t-test used to check the degree of significance using SPSS software 21

\section{RESULTS}

The results of this work show that after supplementing metabolic syndrome patients with vitamin D3 and selenium, serum vitamin D3 significantly increase to near normal value Figure 1.

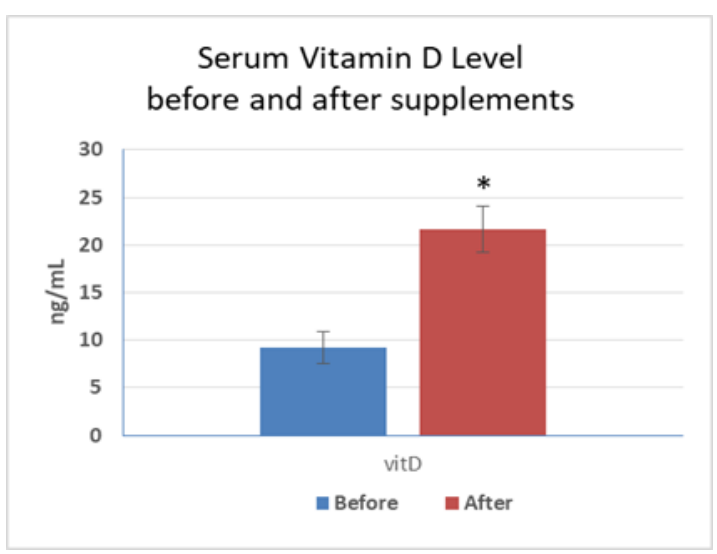

Figure 1. Serum Vitamin D3 levels before and after Vitamin D3 and Selenium supplements.

There was a significant reduction on both systolic and diastolic blood pressure after the supplementing intervention Figure 2.

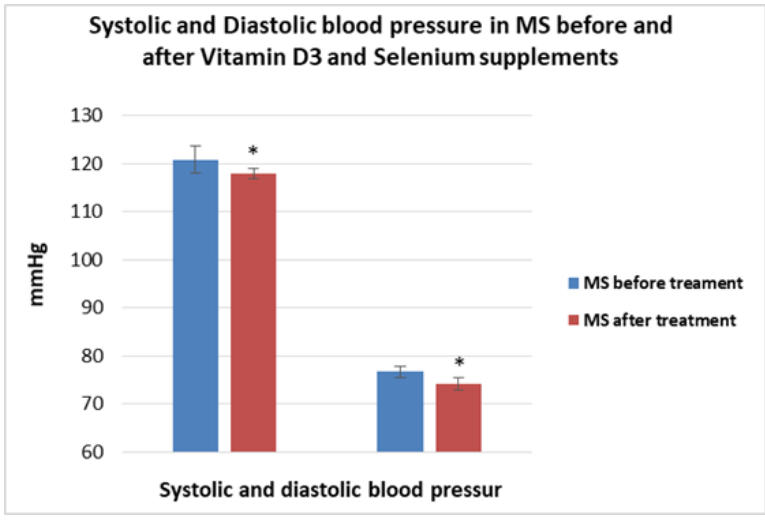

Figure 2. Systolic and Diastolic blood pressure in MS before and after Vitamin D3 and Selenium supplements

Lipid profile results show that the treatment has no significant effect on total serum cholesterol while the treatment causes a significant reduction in serum triglycerides level $(p<0.001)$ and significant elevation in HDL-C level ( $p<0.001$ ) in comparison to before treatment levels table1.
Table 1. Lipid profile changes in MS patients before and after Vitamin D3 and selenium supplements

\begin{tabular}{|c|c|c|c|}
\hline $\begin{array}{l}\text { Lipid Profile } \\
\text { parameter }\end{array}$ & $\begin{array}{l}\text { MS before } \\
\text { treatment }\end{array}$ & $\begin{array}{l}\text { MS after } \\
\text { treatment }\end{array}$ & $\begin{array}{l}p \text { - } \\
\text { value }\end{array}$ \\
\hline $\begin{array}{l}\text { Total } \\
\text { cholesterol, } \\
\mathrm{mg} / \mathrm{dL}\end{array}$ & $192.2 \pm 23.8$ & $189.4 \pm 19$ & 0.36 \\
\hline $\begin{array}{l}\text { Triglyceride, } \\
\mathrm{mg} / \mathrm{dL}\end{array}$ & $146.9 \pm 6.4$ & $130.1 \pm 13.8$ & 0.000 \\
\hline $\begin{array}{l}\text { HDL- } \\
\text { cholesterol, } \\
\mathrm{mg} / \mathrm{dL}\end{array}$ & $43.2 \pm 6.9$ & $51.5 \pm 6.6$ & 0.000 \\
\hline
\end{tabular}

MS patient's glycaemic profile shows that m-HbA1C, pHbA1C, Fructosamine and mean blood glucose significantly reduced after treatment Table 2 .

Table 2. Glycemic profile of MS patients before and after Vitamin D3 and Selenium supplements

\begin{tabular}{|c|c|c|c|}
\hline $\begin{array}{l}\text { Glycemic } \\
\text { parameter }\end{array}$ & $\begin{array}{l}\text { MS before } \\
\text { treatment }\end{array}$ & $\begin{array}{l}\text { MS after } \\
\text { treatment }\end{array}$ & $\begin{array}{c}p \text { - } \\
\text { value }\end{array}$ \\
\hline m-HbA1c, \% & $6.3 \pm 0.51$ & $5.1 \pm 0.31$ & 0.000 \\
\hline p-HbA1c & $5.8 \pm 0.26$ & $5.5 \pm 0.21$ & 0.001 \\
\hline $\begin{array}{l}\text { Fructosamine, } \\
\mu \mathrm{mol} / \mathrm{L}\end{array}$ & $248.5 \pm 15$ & $230.5 \pm 12.6$ & 0.000 \\
\hline $\begin{array}{l}\text { Fasting plasma } \\
\text { glucose, mg/dL }\end{array}$ & $99.9 \pm 12$ & $98.1 \pm 6.4$ & 0.19 \\
\hline $\begin{array}{l}\text { Mean blood } \\
\text { glucose, mmol/L }\end{array}$ & $6.6 \pm 0.45$ & $6.1 \pm 0.38$ & 0.000 \\
\hline
\end{tabular}

Glycosylation gap significantly reduced after treatment with vitamin D3 and Selenium supplements figure 3.

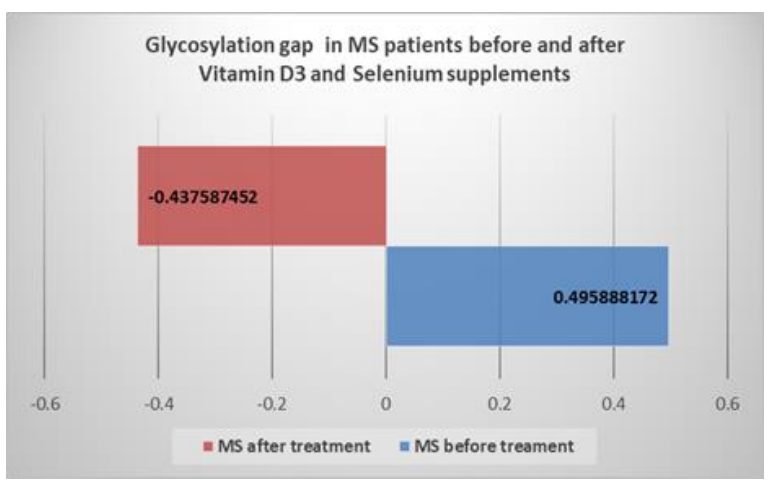

Figure 3. Glycosylation Gap of MS patients before and after Vitamin D3 and Selenium supplements

Renal function profile shows that serum creatinine significantly elevated after the treatment in contrast eGFR, urinary albumin and Albumin/ creatinine ratio 
reduced after the treatment. Urine creatinine shows no significant change after the treatment Table 3.

Table 3. Renal function profile in MS patients before and after Vitamin D3 and Selenium supplements.

\begin{tabular}{|c|c|c|c|}
\hline $\begin{array}{l}\text { Renal Profile } \\
\text { parameter }\end{array}$ & $\begin{array}{l}\text { MS before } \\
\text { treatment }\end{array}$ & $\begin{array}{l}\text { MS after } \\
\text { treatment }\end{array}$ & $\begin{array}{c}p- \\
\text { value }\end{array}$ \\
\hline $\begin{array}{l}\text { Serum } \\
\text { creatinine, } \\
\mathrm{mg} / \mathrm{dL}\end{array}$ & $0.64 \pm 0.05$ & $0.82 \pm 0.12$ & 0.000 \\
\hline $\begin{array}{l}\text { e-GFR, } \\
\mathrm{ml} / \mathrm{min} / 1.73 \\
\mathrm{~m} 2\end{array}$ & 111. $4 \pm 10.8$ & $95.5 \pm 8.9$ & 0.001 \\
\hline $\begin{array}{l}\text { Urine } \\
\text { creatinine, } \mathrm{g} / \mathrm{dL}\end{array}$ & $1.28 \pm 0.08$ & $1.28 \pm 1.12$ & 0.91 \\
\hline $\begin{array}{l}\text { Urine albumin, } \\
\mathrm{mg} / \mathrm{dL}\end{array}$ & $0.16 \pm 0.014$ & $0.13 \pm 0.017$ & 0.001 \\
\hline $\begin{array}{l}\text { Albumin / } \\
\text { Creatinine ratio } \\
\mathrm{mg} / \mathrm{g}\end{array}$ & $0.13 \pm 0.013$ & $0.11 \pm 0.018$ & 0.001 \\
\hline
\end{tabular}

Mitochondrial function profile shows that after supplements treatment, mitochondrial function parameters return to normal values in comparison to before treatment $(\mathrm{p}<0.001)$ Table 4.

Table 4. Mitochondrial function profile before and after vitaminD3 and Selenium supplements.

\begin{tabular}{|c|c|c|c|}
\hline $\begin{array}{c}\text { Mitochondrial } \\
\text { function Profile } \\
\text { parameter }\end{array}$ & $\begin{array}{l}\text { MS before } \\
\text { treatment }\end{array}$ & $\begin{array}{l}\text { MS after } \\
\text { treatment }\end{array}$ & $\begin{array}{c}p \text { - } \\
\text { value }\end{array}$ \\
\hline $\begin{array}{l}\text { Serum Lactate } \\
(\mu \mathrm{M})\end{array}$ & $1653 \pm 107$ & $1263 \pm 301$ & 0.0001 \\
\hline $\begin{array}{l}\text { Serum } \\
\text { Pyruvate }(\mu \mathrm{M})\end{array}$ & $69.8 \pm 3.7$ & $67.8 \pm 12$ & 0.126 \\
\hline $\mathrm{L} / \mathrm{P}$ ratio & $23.71 \pm 1.35$ & $18.99 \pm 4.3$ & 0.0001 \\
\hline L-Carnitine $(\mu \mathrm{M})$ & $12.86 \pm 2.34$ & $27.7 \pm 17.4$ & 0.0001 \\
\hline
\end{tabular}

\section{DISCUSSION}

Metabolic syndrome (MS) is one of the major public health problems worldwide. MS-associated with state of oxidative stress, pro-inflammation coagulopathy and insulin resistance all these factors will have a direct effect in renal function in this group of patients5. The kidney participates in the regulation of many physiological functions as the excretory activity, water and electrolytes balance, acid-base homeostasis. Moreover, the kidney has an endocrine function to the production of vital hormones such as renin, prostaglandins, erythropoietin, and calcitriol all these will change in metabolic syndrome 22 .

The oxidative stress status in the kidney leads to significant deterioration of renal function due to exhaustion of antioxidant activity such as Glutathione peroxidase-1 (Gpx1) seleno-antioxidant enzyme that expressed in the kidney to detoxified free radical as peroxides and peroxynitrite that can cause significant renal damage as described by Haan et al, supplementing metabolic syndrome patients with selenium provide the core of this enzyme23. Jhee et al, described very low vitamin D significantly associated with increasing prevalence of renal hyper filtration in control adult and this can help in explanation how can supplementing metabolic syndrome patient with vitamin D3 can correct hyper filtration status 24 .

Despite that, systolic and diastolic blood pressure affected by many factors as age, race, using tobacco, high salt intake other than vitamin D and Selenium levels25. This work aims to explain the pattern of blood pressure changes after correction of vitamin D and selenium supplements. Many studies described as the effect of vitamin D deficiency on blood pressure 26,27,28,29, $30,31,32$. All these works relate the changes in blood pressure due to role of vitamin D in regulation of reninangiotensin-aldosterone system as low vitamin D increase plasma renin level33,34 and erythropoietin produced in interstitial fibroblast cells in the renal cortex. Low serum vitamin $D$ leading to decrease in renal mass thus reduce both erythropoietin production and 1- $\alpha$ hydroxylation of Vitamin D34,30. Low selenium level in metabolic syndrome individual affecting blood pressure in metabolic syndrome patient 35 by affecting selenoproteins enzymes that included in may vital function such as antioxidant glutathione peroxidase enzyme prevents oxidation of lipids and phospholipids 30 . Low selenium level associated with inhibition of endotheliumdependent-relaxation due to elevation in hydroperoxides, which inhibit prostacyclin- synthetase -an enzyme responsible for the production of the vasodilatory-prostacyclin- by the endothelium. The low selenium level associated with oxidative stress stimulates the production of thromboxane lead to vasoconstriction and platelet aggregation. Moreover, normal selenium maintains adequate nitric oxide concentration and to reduce LDL oxidation30. Redox scavenger role of selenium is vital in restoration of damaged islets and vascular tissues due to hyperglycemic associated metabolic syndrome36. Jiang et al described low vitamin D associated with dyslipidemia that characterized by high LDL cholesterol and triglycerides levels, and low HDL cholesterol level 37. Selenium administration improving lipid modulation and oxidative status by downregulates mRNA expression of Ppar- $\gamma$ and activating Ppar- $\alpha$ expression in the liver leading to elevating fatty acid oxidation33.

Metabolic syndrome patients possess with insulin resistance that changes insulin/phosphatidylinositol 3kinase/Akt and mTOR axis signaling leading to induce podocyte hypertrophy that associated with glomerulus enlarges, increase renal plasma flow, GFR and tubular sodium reabsorption. Moreover, accumulation of adipokines and ectopic lipid in the kidney promotes renal hyper-filtration status with different degree of 
proteinuria38. Supplementation with vitamin D reduces the insulin resistance in the tissue and reduces excessive insulin secretion resulting increases insulin sensitivity39,40. Raygan et al described that Selenium supplementation significantly decreases serum insulin level and HOMA-IR, LDL-cholesterol, total cholesterol and a significant elevation in serum HDL cholesterol41.

This work may be the first who described the impact of vitamin D and selenium supplements on mitochondrial function parameters, which shows a significant reduction in $\mathrm{L} / \mathrm{P}$ ratio that considered as a main indirect tool to evaluate the mitochondrial function and the result, reflect that mitochondrial function return to normal after supplements intervention. L-carnitine plays a vital role in many aspects of lipid metabolism; in metabolic syndrome patients; serum total carnitine significantly reduced; this may be related to an increase in urinary carnitine excretion42. Supplements with vitamin D and selenium significantly increase serum L-carnitine and that may relate to the correction of hyper-filtration status.

\section{CONCLUSION}

To sum up, Vitamin D3 and Selenium supplementation to metabolic syndrome patient corrected hyper-filtration status and mitochondrial function in these patients, so it used as a protective measure in the treatment of metabolic syndrome patients.

\section{REFERENCES}

[1] Tran BT, Jeong BY, Oh JK. The prevalence trend of metabolic syndrome and its components and risk factors in Korean adults: results from the Korean National Health and Nutrition Examination Survey 2008-2013. BMC Public Health. 2017;17(1):1-8. doi:10.1186/s12889-016-3936-6

[2] McCracken E, Monaghan M, Sreenivasan S. Pathophysiology of the metabolic syndrome. Clin Dermatol. 2018;36(1):14-20. doi: 10.1016/j.clindermatol.2017.09.004

[3] O’Neill S, O'Driscoll L. Metabolic syndrome: A closer look at the growing epidemic and its associated pathologies. Obes Rev. 2015;16(1):1-12. doi:10.1111/obr.12229

[4] Ann L Coker. Metabolic Syndrome: Genetic Insights into Disease Pathogenesis HHS Public Access. Physiol Behav. 2017;176(5):139-148. doi: 10.1016/j.physbeh.2017.03.040

[5] Raikou V, Gavriil S. Metabolic Syndrome and Chronic Renal Disease. Diseases. 2018;6(1):12. doi:10.3390/diseases6010012

[6] Ratliff BB, Abdulmahdi W, Pawar R, Wolin MS. Oxidant mechanisms in renal injury and disease. Antioxidants Redox Signal. 2016; 25(3):119-146. doi:10.1089/ars.2016.6665
[7] Nita M, Grzybowski A. The Role of the Reactive Oxygen Species and Oxidative Stress in the Pathomechanism of the Age-Related Ocular Diseases and Other Pathologies of the Anterior and Posterior Eye Segments in Adults. Oxid Med Cell Longev. 2016; 2016. doi:10.1155/2016/3164734

[8] Kanbay M, Ertuglu LA, Afsar B, et al. Renal hyperfiltration defined by high estimated glomerular filtration rate: A risk factor for cardiovascular disease and mortality. Diabetes, Obes Metab. 2019;21(11):2368-2383. doi:10.1111/dom.13831

[9] Reboldi G, Verdecchia P, Fiorucci G, et al. Glomerular hyperfiltration is a predictor of adverse cardiovascular outcomes. Kidney Int 2018;93(1):195-203. doi: 10.1016/j.kint.2017.07.013

[10] Raghav A, Ahmad J, Alam K. Nonenzymatic glycosylation of human serum albumin and its effect on antibodies profile in patients with diabetes mellitus. PLoS One. 2017;12(5). doi: 10.1371/journal.pone.0176970

[11] Muda U, Reserve F, Pdf R. 0 New 00 New 21 2020;2020(3):2-4. doi:10.13140/RG.2.2.15032.80647

[12] Pourvaghar MJ, Bahram ME, Sayyah M, et al. Adiponectin, insulin sensitivity and diabetic retinopathy in latinos with type 2 diabetes. J Clin Endocrinol Metab. 2016;11(1):3348-3355. doi:10.4103/ijem.IJEM

[13] Debray FG, Mitchell GA, Allard P, Robinson BH, Hanley JA, Lambert M. Diagnostic accuracy of blood lactate-to-pyruvate molar ratio in the differential diagnosis of congenital lactic acidosis. Clin Chem. 2007;53(5):916-921. doi:10.1373/clinchem.2006.081166

[14] Longo N, Frigeni M, Pasquali M. Carnitine transport and fatty acid oxidation. Biochim Biophys Acta - Mol Cell Res. 2016;1863(10):2422-2435. doi: 10.1016/j.bbamcr.2016.01.023

[15] Carr, R. M., Oranu, A., \& Khungar V. 乳鼠心肌提 取 HHS Public Access. Physiol Behav. 2016; 176(1):139-148. doi: 10.1016/j.physbeh.2017.03.040

[16] Biomérieux. VIDAS ® $25 \mathrm{OH}$ Vitamin D TOTAL. 2013:1-8

[17] M. Alkataan. Glycosylation gap in-group obese subjects. Iraq J Pharm 2013; 13(2). https://iphr.mosuljournals.com/article_86550_72409 eca8ca3d850d3fee482efbda345.pdf

[18] No I. L-Lactate Assay Kit. https://www.caymanchem.com/product/700510/1lactate-assay-kit

[19] K- C, Store C. Pyruvate Assay Kit. (700470):650.

[20] Kit HE. oS ou yB i oS. :6-9.

[21] Estimated Glomerular Filtration Rate. Definitions. doi:10.32388/2s9syw 
[22] Wesson DE, Buysse JM, Bushinsky DA. Mechanisms of metabolic acidosis-induced kidney injury in chronic kidney disease. J Am Soc Nephrol. 2020;31(3):469-482. doi:10.1681/ASN.2019070677

[23] De Haan JB, Stefanovic N, Nikolic-Paterson D, et al. Kidney expression of glutathione peroxidase- 1 is not protective against streptozotocin-induced diabetic nephropathy. Am J Physiol - Ren Physiol. 2005;289(3 doi:10.1152/ajprenal.00088.2005 58-3):F544-F551.

[24] Jhee JH, Nam KH, An SY, et al. Severe Vitamin D deficiency is a risk factor for renal hyperfiltration. Am J Clin Nutr. 2018;108(6):1342-1351. doi:10.1093/ajen/nqy194

[25] Mehta V, Agarwal S. Does Vitamin D Deficiency Lead to Hypertension? Cureus. 2017;9(2):2-9. doi:10.7759/cureus. 1038

[26] He S, Hao X. The effect of vitamin D3 on blood pressure in people with vitamin D deficiency: A system review and meta-analysis. Medicine (Baltimore). 2019;98(19):e15284. doi:10.1097/MD.0000000000015284

[27] Weng S, Sprague JE, Oh J, et al. Vitamin D Deficiency Induces High Blood Pressure and Accelerates Atherosclerosis in Mice. PLoS One. 2013;8(1). doi: 10.1371/journal.pone.0054625

[28] Rowe. 基因的改变 NIH Public Access. Bone. 2008;23(1):1-7. doi:10.1038/jid.2014.371

[29] Li YC, Qiao G, Uskokovic M, Xiang W, Zheng W, Kong J. Vitamin D: A negative endocrine regulator of the renin-angiotensin system and blood pressure. J Steroid Biochem Mol Biol. 2004;89-90:387-392. doi:10.1016/j.jsbmb.2004.03.004

[30] Nawrot TS, Staessen JA, Roels HA, et al. Blood pressure and blood selenium: A cross-sectional and longitudinal population study. Eur Heart J. 2007;28(5):628-633. doi:10.1093/eurheartj/ehl479

[31] Benstoem C, Goetzenich A, Kraemer S, et al. Selenium and its supplementation in cardiovascular disease - what do we know? Nutrients. 2015;7(5):3094-3118. doi:10.3390/nu7053094

[32] Błazewicz A, Klatka M, Astel A, et al. Serum and urinary selenium levels in obese children: A crosssectional study. J Trace Elem Med Biol. 2015; 29:116-122. doi: 10.1016/j.jtemb.2014.07.016

[33] Santoro D, Caccamo D, Lucisano S, et al. Interplay of Vitamin D, erythropoiesis, and the reninangiotensin system. Biomed Res Int. 2015;2015. doi: $10.1155 / 2015 / 145828$

[34] Zittermann A, Ernst JB, Prokop S, et al. Effects of Vitamin D Supplementation on Renin and Aldosterone Concentrations in Patients with Advanced Heart Failure: The EVITA Trial. Int $\mathbf{J}$ Endocrinol. 2018;2018. doi:10.1155/2018/5015417

[35] Ghayour-Mobarhan M, Taylor A, Lanham-New S, et al. Serum selenium and glutathione peroxidase in patients with obesity and metabolic syndrome. Pakistan J Nutr. 2008;7(1):112-117. doi:10.3923/pjn.2008.112.117

[36] Shi Y, Zou Y, Shen Z, et al. Trace elements, PPARs, and metabolic syndrome. Int J Mol Sci. 2020;21(7). doi:10.3390/ijms21072612

[37] Jiang X, Peng M, Chen S, Wu S, Zhang W. Vitamin $\mathrm{D}$ deficiency is associated with dyslipidemia: a crosssectional study in 3788 subjects. Curr Med Res Opin. 2019;35(6):1059-1063. doi:10.1080/03007995.2018.1552849

[38] D’Agati VD, Chagnac A, De Vries APJ, et al. Obesity-related glomerulopathy: Clinical and pathologic characteristics and pathogenesis. Nat Rev Nephrol. 2016;12(8):453-471 doi:10.1038/nrneph.2016.75

[39] Durmaz ZH, Demir AD, Ozkan T, Kilinç Ç, Güçkan R, Tiryaki M. Does vitamin D deficiency lead to insulin resistance in obese individuals? Biomed Res. 2017;28(17):7491-7497.

[40] Tang H, Li D, Li Y, Zhang X, Song Y, Li X. Effects of Vitamin D supplementation on glucose and insulin homeostasis and incident diabetes among nondiabetic adults: A meta-analysis of randomized controlled trials. Int J Endocrinol. 2018;2018. doi:10.1155/2018/7908764

[41] Raygan F, Behnejad M, Ostadmohammadi V, et al. Selenium supplementation lowers insulin resistance and markers of cardio-metabolic risk in patients with congestive heart failure: A randomised, double-blind, placebo-controlled trial. Br J Nutr. 2018;120(1):3340. doi:10.1017/S0007114518001253

[42] Hoppel CL, Genuth SM. Carnitine metabolism in normal-weight and obese human subjects during fasting. Am J Physiol - Endocrinol Metab. 1980;1(5):3-5.

doi:10.1152/ajpendo.1980.238.5.e409 